Zeitschrift für Kinderheilkunde 97, 100 (1966)

\title{
Corrigendum
}

\section{Asphyxia neonatorum}

II. Mitteilung

Die Behandlung mit vasodilatorischen und vagolytischen Substanzen

H. Menttzel

Zeitschrift für Kinderheilkunde 96, 132-140 (1966)

Die Arbeit enthält einen bedauerlichen Druckfehler, der nach dem Imprimatur entstanden ist.

Die Fußnote 2 auf Seite 136 muß richtig lauten:

2 Zusammensetzung von Perphyllon A/XII: $2 \mathrm{~cm}^{3}$ enthalten: 42,5 mg 7-( $\beta$ Hydroxyäthyl)-theophyllin, 12,5 mg Theophyllin, $30 \mathrm{mg}$ Papaverin, 0,3 mg Eumydrin Bayer. 